\title{
Comparison of Air Pollution by VOCs Inside the Cabins of New Vehicles
}

\author{
Joanna Faber ${ }^{1}$, Krzysztof Brodzik ${ }^{1}$, Anna Gołda-Kopek ${ }^{1}$, Damian Łomankiewicz ${ }^{1}$, Jan Nowak ${ }^{1}$ \& Antoni Świątek ${ }^{1}$ \\ ${ }^{1}$ BOSMAL Automotive Research and Development Institute Ltd, Bielsko-Biała, Poland \\ Correspondence: Joanna Faber, BOSMAL Automotive Research and Development Institute Ltd, Sarni Stok 93, \\ 43-300 Bielsko-Biała, Poland. Tel: 48-33-813-0404. E-mail: joanna.faber@bosmal.com.pl
}

Received: May 21, 2013 Accepted: June 13, 2014 Online Published: June 8, 2014

doi:10.5539/enrr.v4n3p155 URL: http://dx.doi.org/10.5539/enrr.v4n3p155

\begin{abstract}
Air composition inside the cabins of nine new vehicles of the same model, but with different interior equipments and materials used, was examined. Air samples were collected short after vehicles' production date. None of the vehicle was driven before sampling. Air pollution was assessed on the basis of the concentration of different volatile organic compounds (VOCs) and total VOC. Since only new vehicles were under study, it can be stated that different VOCs, present in vehicle cabin, were emitted from interior materials. The main aim of the present work was to answer the question about the representativeness of collected air samples and intra-model variability of VOCs concentrations. Air samples were collected by an active method onto duplicate Carbograph 1TD and Tenax TA sorbents. VOCs were thermally desorbed and analyzed with the use of the TD-GC-FID/MS method. Quantitative and qualitative analyses as well as statistical calculations were performed. Total VOCs concentration ranged from 1.5 to $2.1 \mathrm{mg} / \mathrm{m}^{3}$ in vehicles tested. About 200 different organic compounds were detected in each vehicle interior. Strong linear correlation was observed for concentrations of some kind of compounds.
\end{abstract}

Keywords: volatile organic compounds, vehicle interior, new vehicle, emission from materials, intra-model variability

\section{Introduction}

Volatile organic compounds (VOCs) are well known air pollutants, both outdoor and indoor (Dettmer \& Engewald, 2002; Idris et al., 2010). Since a vehicle's interior is regarded as specific indoor environment (Grabbs et al., 2000; Jo \& Park, 1999; Mandalakis et al., 2008; Riediker et al., 2003; Weisel, 2005; Yoshida et al., 2006a), it is an important pathway of human exposure to different VOCs. It is estimated that people spend about $6-8 \%$ of their time inside vehicle cabins (Klepeis et al., 2001). Taking into account that the concentrations of different organic compounds within vehicles may be as much as three times higher than in other indoor environments (Ilgen et al., 2001; Mandalakis et al., 2008; Weisel, 2005; Yoshida \& Matsunaga, 2006), the long-term exposure of a car user to VOCs is of the highest importance.

In new vehicles concentrations of various organic compounds are significantly higher than in used vehicles. This can be observed on the basis of benzene, toluene and sum of xylenes concentrations. Although those compounds are known to be exhaust gases emission markers, their concentrations in new vehicles were even ten times higher than in used vehicles. Concentrations of toluene and isomers of xylene increased with the mileage increase, but did not exceed the initial concentrations (Faber et al., 2013a).

Volatile organic compounds' presence inside a new vehicle is mostly connected with interior emission from materials used to equip the passenger compartment (materials off-gassing). The materials which are the main sources of VOCs emission include hard plastics, elastomers, rubber, natural or synthetic leather, fabrics and fibres; all of them may be mentioned in connection with this issue (Chien, 2007; Fedoruk \& Kerger, 2003; Grabbs et al., 2000; Mandalakis et al., 2008; Yoshida \& Matsunaga, 2006; Yoshida et al., 2006a; You et al., 2007). The interior trim materials (leather or fabric) significantly affects VOCs levels within a vehicle (Chien, 2007; Kalman et al., 2000). For example, floor carpets may be one of the sources of styrene emission (Grabbs et al., 2000), while 1-butanol and 2,6-di-t-butyl-4-methyl phenol are characteristic for interiors with different plastics, rubbers and resins (Yoshida et al., 2006b). The influence of interior equipment on in-vehicle air quality as well as the differences in materials used on VOCs concentrations were described by Brodzik et al. (2014). 
The concentration of VOCs observed depends mostly on interior temperature, humidity, ventilation, age and the general condition of vehicle (Chien, 2007; Faber et al., 2012; Fedoruk \& Kerger, 2003; Mandalakis et al., 2008; Rahman \& Kim, 2012; Yoshida et al., 2006a; Yoshida \& Matsunaga, 2006; You et al., 2007). Interior temperature seems to be an especially important factor influencing VOCs emission, because during summer days the temperature in car cabin may exceed $65^{\circ} \mathrm{C}$. The increased temperature inside a car cabin may provoke increased vaporization and off-gassing of various organic compounds from interior materials. Many studies have described interior air quality in used vehicles and research on VOC concentration originating from exterior sources. In comparison, only a few investigations have been performed on interior emission in new, unused, vehicles (Geiss et al., 2009; Grabbs et al., 2000; Yoshida \& Matsunaga, 2006; Yoshida et al., 2006b), and in most cases the number of vehicles tested was limited (Yoshida et al., 2006a). Zhang et al. (2008) tested 802 new private vehicles (some of which were up to 3 years old). In that study, only four organic compounds were investigated. In another investigation, Yoshida and Matsunaga (2006) determined as many as 161 organic compounds, but they tested only one private car. You et al. (2007) identified 82 compounds in a single new car; 61 compounds in a one year-old car and 36 compounds in a five year-old car. Chien (2007) investigated 12 of the most often detected compounds in five different, new vehicles. On the basis of the tests performed, it was stated that concentrations of particular compounds differed significantly by vehicle model. Comparison of air composition in different car models produced in Poland was described by Faber et al. (2013b). The number of identified compounds depended on vehicle model and equipment, and ranged between 57 and 103 compounds. Brodzik et al. (2014) investigated air composition in nine new vehicles of the same model, but with different interior equipment. Differences in materials used to finish vehicle's cabin affected the number of organic compounds emitted, which ranged from 139 to 210. The widest field of investigations were performed by Yoshida et al. (2006a; 2006b), who tested 101 Japanese vehicles of age up to three years old. They identified 275 different organic compounds, of which 242 compounds were present in each vehicle tested.

In the aforementioned studies VOCs concentration was found to be from 136 to $14,081 \mu \mathrm{g} / \mathrm{m}^{3}$, with an average value of a few $\mathrm{mg} / \mathrm{m}^{3}$. Fedoruk and Kerger (2003) found that the main pollutants inside the two new cars they tested included toluene, phenol, methyldecanes and styrene. You et al. (2007) reported that the main group of pollutants in a new vehicle were alkanes and aromatic compounds, with decane and $m, p$-xylene concentrations of $345 \mu \mathrm{g} / \mathrm{m}^{3}$ and $350 \mu \mathrm{g} / \mathrm{m}^{3}$ at the highest concentration levels, respectively. Yoshida and Matsunaga (2006) also identified aliphatic and aromatic hydrocarbons as the main groups of pollutants with a concentration of 6011.7 and $5946.8 \mu \mathrm{g} / \mathrm{m}^{3}$, respectively. The highest concentrations were found for $m, p$-xylene, undecane and decane and were $3104.0,1615.8$ and $1300.6 \mu \mathrm{g} / \mathrm{m}^{3}$, respectively. In various vehicles, Faber et al. (2013b) identified aliphatic compounds to be the main group of pollutants. In tested vehicles, Brodzik et al. (2014) found that the main compounds were undecane, isomers of xylene and toluene. Chien (2007) reported that intra-model variability in VOC concentration was at an average level of $47 \%$, while VOCs between different brands varied within $95 \%$.

The aim of present work was to examine the representativeness of air samples collection and to verify intra-model variability of air composition inside nine new vehicles of one car manufacturer. The present study focused on organic compounds, emitted from interior finishing materials. Those compounds were responsible for interior air quality. The fact that new, unused vehicles were under study represents the worst case in terms of VOCs concentrations. The following areas were examined in the present study: (i) qualitative analysis (identification) of VOCs, (ii) total concentration of VOCs emitted, (iii) quantitative analysis of single VOCs collected from new vehicles' cabins. Moreover, the precision of air sampling was described. To our best knowledge this is the first study in this area of Europe on air quality inside new vehicles and detailed intra-model variability. A completed study on VOCs analysis and their repeatability is presented.

\section{Methodology}

\subsection{Vehicles Under Study}

Nine new vehicles of the same model were examined. The vehicle model tested was a compact car produced domestically in Poland for domestic and global market. All examples of the model were tested less than one week from their date of production and were not driven before air sampling. The cars examined were parked in an outdoor parking area. Vehicles had no fuel leakages or mechanical problems. The passenger compartments were completely free of cigarette smoke, deodorizers and fresheners. All the cars named M1 (M1_1...M1_5) had the same interior equipment: black-grey fabric upholstery, a black plastic steering wheel and a grey dashboard; whereas cars named M2 (M2_1...M2_4) were equipped with black suede upholstery, a black leather-like steering wheel and black dashboard. The remaining interior equipment (for example headlining, carpet or sealing) was identical in all the vehicles under study. Accordingly, intra-model variations in VOCs levels were examined. 


\subsection{Air Sampling}

Air samples were collected from the vehicles' interiors under static conditions (vehicle's engine was shut off, all doors and windows were closed, AC was off), at about $50 \mathrm{~cm}$ above the driver's seat (approximately in the driver's breathing zone). VOCs emitted by interior materials were collected onto two parallel glass tubes filled with 100 mg of Carbograph 1TD (graphitized carbon black, 40/60 mesh, medium/weak sorption strength; Markes, UK) and two parallel stainless steel tubes filled with $200 \mathrm{mg}$ Tenax TA (porous polymer sorbent, 35/60 mesh, weak sorption strength; Markes, UK). For each sorbent material samples were collected as replicate, therefore four samples were taken from each vehicle.

Air samples from the vehicles' cabins were collected with the use of air pumps (PCM TX-8, SKC, UK) with calibrated and controlled air flow at a rate of $100 \mathrm{~mL} / \mathrm{min}$. The total sampled air volume was $2 \mathrm{~L}$ in each case. The influence of outdoor air was reduced to a minimum since the vehicle's doors were open not longer than $10 \mathrm{sec}$ during installation of duplicate sorbents connected to the air pumps (Chien, 2007). The sampling device was switched on manually. Field blank samples were collected alongside samples from the vehicles' interiors.

The tubes with air samples were sealed with Swagelok brass end caps fitted with PTFE ferrules, transported to the laboratory in a sealed plastic box and stored at $4^{\circ} \mathrm{C}$ until analysis was performed (within max 1 week).

Interior temperature and relative humidity $(\% \mathrm{RH})$ were measured using a thermohygrometer (LB-702, LAB-EL, Poland). The temperature and relative humidity inside vehicles ranged from 18.9 to $23.8^{\circ} \mathrm{C}$, and 21 to $58 \% \mathrm{RH}$, respectively. The average atmospheric conditions during the sampling event were $21.7^{\circ} \mathrm{C}$ and $44 \% \mathrm{RH}$. Influence of temperature on VOCs concentration in vehicle interior was described in details elsewhere (Faber et al., 2012).

\subsection{Gas Chromatographic Analysis}

Analytes from collected air samples were thermally desorbed from the sorbent (Unity2, Markes, UK) and analysed using a gas chromatograph equipped with a flame ionisation detector coupled with a mass detector (TD-GC-FID/MS). The gas chromatograph was equipped with a column splitter which permitted simultaneous analysis on both the FID and MS detectors. The parameters of thermal desorption and chromatography analysis, as well as the equipment used were described elsewhere (Faber et al., 2013b).

Organic compounds were identified by their retention times $\left(t_{R}, \min \right)$ and mass spectra in comparison to NIST 08 library. The target compounds were confirmed by their retention times on the basis of analysis of standard solutions. All compounds at concentrations above $1 \mu \mathrm{g} / \mathrm{m}^{3}$, with scores above $80 \%$ according to NIST library (Grabbs et al., 2000; Chien, 2007) were regarded as identified compounds $\left(\mathrm{VOC}_{\mathrm{id}}\right)$. Identification was confirmed for 65 compounds determined in vehicles from their chromatographic retention times and mass spectra (Table 1). Concentration of all $\mathrm{VOC}_{\mathrm{id}}$ obtained from FID were calculated in toluene equivalent $\left(\mu \mathrm{g} / \mathrm{m}^{3}\right)$, meaning that they were calculated against the standard toluene curve (You et al., 2007; Buters et al., 2007). The group of aliphatic hydrocarbons included alkanes and alkenes, while cycloalkanes were regarded as a separate class of compounds. Compounds which were determined and identified - but not confirmed - were reported as 'others'.

The standard solutions used contained the following mix of organic compounds (Table 1): S-19078 (AccuStandard, Inc, USA, of minimum purity 98\%), containing 10 aliphatic hydrocarbons, 4 aromatic hydrocarbons and 1 alcohol at $2000 \mathrm{mg} / \mathrm{L}$ in methanol; GRO-AK-101AA-ARO (AccuStandard, Inc, USA, of minimum purity 98\%), containing 14 aromatic hydrocarbons at $2000 \mathrm{mg} / \mathrm{L}$ in methanol; PIANO Aromatics Mix (AccuStandard, Inc, USA) containing 38 aromatic hydrocarbons; Alphagaz PIANO Isoparaffins Mix (Sigma-Aldrich, USA) containing 35 isoparaffins; PIANO Naphthenes Mix (Sigma-Aldrich, USA), containing 30 naphthenes. Additionally, single compounds standard solutions were used: acetone, 2-butanone, 2-metoxyethanol, phenol, $\alpha$-pinene, limonene, benzaldehyde, aniline (Sigma-Aldrich, USA); hexane, hexanol, cyclohexanone, styrene and butyl acetate (Supelco, USA). To sum up, 105 different organic compounds were analysed.

Each stock standard solution was diluted in methanol to obtain proper working standard solutions, then a volume of $2 \mu \mathrm{L}$ of solution was spiked onto sorbent tubes, thermally desorbed and analysed by gas chromatography with flame ionisation and mass detectors (TD-GC-FID/MS). Calibration curves of five points were prepared. Obtained calibration parameters, method precision and recoveries were described elsewhere (Faber, 2013b).

The sum of emitted volatile organic compounds concentrations included all compounds emitted from interior materials into the vehicle's cabin, which were possible to adsorb onto Carbograph 1TD and Tenax TA. Strong linear correlations of concentrations obtained between sorbents were also observed for all compounds $\left(\mathrm{R}^{2}>0.80\right)$.

The results presented in Table 1 for each tested vehicle are the mean of four replicates (two from Carbograph 1TD and two from Tenax TA). Both sorbents were used as complementary. Calculation of the mean concentration from 
two different sorbents was possible because the differences in concentrations for single compounds between sorbents were less than $10 \%$.

\subsection{Quality Control}

Quality control included sampling of duplicate air samples, check of breakthrough volume, field blanks and analysis of an internal standard (deuterated toluene).

Eighteen pairs of duplicate air samples were collected from the nine different vehicles' cabins. Sampling of duplicate samples was performed simultaneously onto two pairs of solid sorbents, connected in parallel to the air pumps. The precision of the sampling method was designated as relative standard deviation (\%RSD) for each pair of duplicate samples, and was considered acceptable where RSD was lower than 20\% (Pankow et al., 1998; EPA, 1999). The concentrations of target compounds in field blank samples were lower than $5 \%$ of the target compounds in real samples.

Breakthrough occurrence was checked by analysis of two tubes connected in row. Concerning results obtained, it can be stated that breakthrough volume for Tenax TA took place only a few compounds lighter than heptane. On the other hand, some compounds with retention times longer than propylbenzene, were not totally adsorbed on Carbograph 1TD. Results obtained are in compliance with sorption strength and properties of each sorbent.

\section{Results and Discussion}

Total VOC emission included all compounds collected from the vehicles' interiors and was in average 2109 and $1505 \mu \mathrm{g} / \mathrm{m}^{3}$ for cars M1 and M2, respectively. However the sum of organic compounds, at concentrations of $1.5-2.1 \mathrm{mg} / \mathrm{m}^{3}$, can be responsible for some irritation or discomfort feelings (AQS, 2006), the results obtained met the proposed by Schupp guidelines: $1-3 \mathrm{mg} / \mathrm{m}^{3}$ of total VOC in vehicle cabin (Schupp et al., 2006).

Although vehicles with different interior equipment differed in VOC level, the total number of detected compounds were similar: 228 in vehicles M1 and 200 in vehicles M2. More than half of those compounds (118 in case of M1s, 128 in case of M2s) were found in $85 \%$ of tested air samples. The total number of identified and confirmed compounds was 55 in cars M1 and 50 in cars M2, which was mostly connected with standard solutions used. The data obtained are in compliance with data presented by Grabbs et al. (2000). The sum of concentrations of confirmed compounds was 1069 and $747 \mu \mathrm{g} / \mathrm{m}^{3}$ for M1 and M2, respectively (Table 1). The confirmed compounds were responsible for at least $50 \%$ of VOCs emission in tested vehicles, meaning that it was possible to identify and confirm $50 \%$ of compounds emitted from materials into vehicle's cabin.

The list of compounds (confirmed and others) detected in each vehicle is presented in Table 1. The concentrations of particular group of compounds were lower in cars M2 than in cars M1, with the exception of aromatic hydrocarbons. Aliphatic hydrocarbons were the prevalent group of air pollutants, with concentrations ranging from 220 to $825 \mu \mathrm{g} / \mathrm{m}^{3}$ (approximately $27 \%$ of total VOC emission, Figure 1), irrespective of interior equipment. The participation of other groups of compounds in total emission was different, aromatic compounds in cars M1 and $\mathrm{M} 2$ were responsible for 9 and $16 \%$ of total VOCs emission, respectively. A reverse situation was observed in the case of cycloalkanes, which were responsible for 7 and $4 \%$ of total VOCs emission in cars M1 and M2, respectively (Figure 1).

Table 2. List of VOCs measured in new vehicles and their concentrations $\left(\mu \mathrm{g} \mathrm{m}^{-3}\right)$

\begin{tabular}{|c|c|c|c|c|c|c|c|c|c|c|c|c|c|c|}
\hline Compound & $\begin{array}{c}\mathbf{t}_{\mathrm{R}}^{(1)} \\
\text { (min.) }\end{array}$ & M1_1 & M1_2 & M1_3 & M1_4 & M1_5 & Mean M1 & $\mathrm{SD}^{(2)} \mathrm{M} 1$ & M2_1 & M2_2 & M2_3 & M2_4 & Mean M2 & $\mathrm{SD}^{(2)} \mathrm{M} 2$ \\
\hline Benzene & 10.38 & 10.1 & 11.0 & 8.6 & 19.6 & 8.0 & 11.4 & 5.5 & 11.9 & 11.7 & 10.4 & 10.5 & 11.1 & 1.0 \\
\hline Toluene & 16.08 & 36.8 & 74.8 & 47.1 & 73.1 & 41.9 & 54.7 & 17.9 & 37.4 & 50.9 & 35.4 & 52.9 & 44.1 & 9.0 \\
\hline Ethylbenzene & 21.90 & 5.9 & 7.6 & 8.1 & 10.2 & 4.3 & 7.2 & 2.2 & 6.2 & 11.1 & 7.6 & 10.2 & 8.8 & 2.3 \\
\hline$m$-Xylene & 22.40 & 14.7 & 17.9 & 20.2 & 26.1 & 10.2 & 17.8 & 6.0 & 17.6 & 31.6 & 20.0 & 28.1 & 24.3 & 6.6 \\
\hline$p$-Xylene & 22.49 & 5.2 & 5.8 & 6.1 & 14.8 & 5.2 & 7.4 & 4.1 & 5.0 & 8.9 & 5.7 & 8.7 & 7.1 & 2.0 \\
\hline Styrene & 23.71 & & & & & & & & 3.8 & 4.6 & 3.7 & 5.2 & 4.3 & 0.7 \\
\hline$o$-Xylene & 23.77 & 12.5 & 18.0 & 14.3 & 23.9 & 11.1 & 16.0 & 5.1 & 8.8 & 17.5 & 11.0 & 14.5 & 12.9 & 3.8 \\
\hline n-Propylbenzene & 26.96 & & & & & & & & 4.8 & 5.8 & 5.0 & 5.8 & 5.4 & 0.5 \\
\hline Isopropylbenzene & 25.40 & 2.6 & 4.4 & 3.1 & 2.1 & & 3.0 & 1.0 & & & & & & \\
\hline 1-Ethyl-3-methylbenzene & 27.26 & 7.8 & 9.0 & 8.0 & 9.9 & 5.6 & 8.1 & 1.6 & 6.7 & 11.3 & 6.2 & 11.6 & 9.0 & 2.9 \\
\hline 1-Ethyl-4-methylbenzene & 27.47 & 17.8 & 25.6 & 18.2 & 10.8 & 7.4 & 16.0 & 7.1 & & & & & & \\
\hline
\end{tabular}




\begin{tabular}{|c|c|c|c|c|c|c|c|c|c|c|c|c|c|c|}
\hline 1,3,5-Trimethylbenzene & 27.70 & & & & & & & & 2.4 & 4.8 & 2.6 & 4.6 & 3.6 & 1.3 \\
\hline 1-Ethyl-2-methylbenzene & 28.22 & 4.5 & 6.7 & 5.4 & 4.5 & 2.1 & 4.6 & 1.7 & 4.9 & 6.7 & 5.3 & 6.9 & 5.9 & 1.0 \\
\hline 1,2,4-Trimethylbenzene & 28.96 & 7.7 & 9.7 & 10.5 & 18.8 & 8.7 & 11.1 & 4.4 & 8.3 & 18.2 & 9.5 & 18.1 & 13.5 & 5.3 \\
\hline 1,2,3-Trimethylbenzene & 30.27 & & & & & & & & 8.2 & 12.8 & 8.9 & 14.0 & 11.0 & 2.9 \\
\hline 1-Methyl-2-isopropylbenzene & 30.85 & 6.6 & 12.6 & 7.7 & 13.2 & 7.6 & 9.5 & 3.1 & 6.0 & 9.1 & 9.5 & 10.6 & 8.8 & 2.0 \\
\hline tert-1-Butyl-2-methylbenzene & 34.87 & 13.8 & 24.6 & 19.5 & 24.8 & 28.5 & 22.2 & 5.7 & 12.6 & 17.7 & 19.4 & 25.3 & 18.8 & 5.3 \\
\hline tert-1-Butyl-4-ethylbenzene & 36.35 & & & & & & & & 3.6 & 5.6 & 4.7 & 7.6 & 5.4 & 1.7 \\
\hline Naphthalene & 36.99 & 3.6 & 5.7 & 5.4 & 5.3 & 4.0 & 4.8 & 0.9 & 2.5 & 4.7 & 3.4 & 6.5 & 4.3 & 1.7 \\
\hline Aromatic compounds & & 139.6 & 222.4 & 173.4 & 237.4 & 136.6 & 181.9 & 46.5 & 200.5 & 266.3 & 219.9 & 261.0 & 237.0 & 31.9 \\
\hline Methylcyclopentane & 8.98 & 3.1 & 3.0 & 2.0 & 10.5 & 7.6 & 5.2 & 3.7 & & & & & & \\
\hline 1,2-Dimethylcyclopentane & 11.75 & & & & & & & & 5.9 & 4.6 & 6.8 & 3.7 & 5.2 & 1.4 \\
\hline Cyclohexane & 10.51 & 7.8 & 9.7 & 5.1 & 13.1 & 11.9 & 9.5 & 3.2 & & & & & & \\
\hline 1,3-Dimethylcyclopentane & 11.47 & 7.8 & 10.4 & 3.7 & 11.6 & & 8.4 & 3.5 & & & & & & \\
\hline trans-1,3-Dimethylcyclopentane & 11.62 & 6.5 & 9.4 & 3.2 & 6.9 & 9.6 & 7.1 & 2.6 & & & & & & \\
\hline 1,2-Dimethylcyclopentane & 11.75 & 11.0 & 14.7 & 4.9 & 14.7 & 6.7 & 10.4 & 4.5 & & & & & & \\
\hline Methylcyclohexane & 13.69 & 59.5 & 129.3 & 54.4 & 64.2 & 28.3 & 67.1 & 37.4 & 22.1 & 15.8 & 22.6 & 13.6 & 18.5 & 4.5 \\
\hline Ethylcyclopentane & 14.19 & 13.3 & 23.4 & 11.2 & 11.8 & 5.6 & 13.0 & 6.5 & 8.1 & 10.5 & 8.0 & 7.1 & 8.4 & 1.4 \\
\hline 1,4-Dimethylcyclohexane & 17.16 & 4.1 & 15.6 & 7.3 & 4.3 & 1.3 & 6.5 & 5.5 & 4.5 & 1.3 & 1.9 & 1.4 & 2.3 & 1.5 \\
\hline 1,3,5-Trimethylcyclohexane & 20.58 & 1.4 & 2.0 & 1.3 & 4.3 & 1.6 & 2.1 & 1.2 & & & & & & \\
\hline 1,2,4-Trimethylcyclohexane & 21.61 & 1.3 & 2.2 & 1.4 & 7.8 & 3.9 & 3.3 & 2.7 & 2.2 & 3.1 & 2.0 & 1.1 & 2.1 & 0.8 \\
\hline Propylcyclohexane & 25.91 & 5.4 & 9.5 & 6.4 & 3.5 & 3.9 & 5.7 & 2.4 & 2.9 & 3.9 & 3.4 & 4.3 & 3.6 & 0.6 \\
\hline 1-Methyl-3-propylcyclohexane & 29.20 & 6.6 & 11.2 & 7.2 & 70.9 & 3.5 & 19.9 & 28.7 & 5.9 & 7.1 & 6.9 & 7.4 & 6.8 & 0.7 \\
\hline 1-Methyl-2-propylcyclohexane & 29.32 & 3.5 & 7.2 & 4.6 & 8.5 & 2.3 & 5.2 & 2.6 & 3.7 & 6.2 & 4.5 & 8.0 & 5.6 & 1.9 \\
\hline Cycloalkanes & & 131.4 & 247.5 & 112.7 & 232.1 & 86.2 & 162.0 & 73.1 & 55.2 & 52.5 & 56.1 & 46.6 & 52.6 & 4.3 \\
\hline Hexane & 7.74 & 2.8 & 7.6 & 3.8 & 9.9 & 5.2 & 5.8 & 2.9 & & & & & & \\
\hline 3,3-Dimethylpentane & 10.06 & 4.7 & 6.6 & 3.8 & 6.7 & 5.6 & 5.5 & 1.2 & 4.5 & 3.1 & 4.5 & 3.6 & 3.9 & 0.7 \\
\hline 2-Methylhexane & 10.42 & 45.8 & 86.8 & 20.7 & 89.6 & 29.3 & 54.5 & 39.2 & 49.6 & 33.2 & 51.7 & 20.1 & 38.7 & 23.0 \\
\hline 2,3-Dimethylpentane & 10.63 & 21.7 & 32.8 & 9.4 & 30.8 & 12.0 & 21.3 & 10.6 & & & & & & \\
\hline 3-Methylhexane & 10.86 & 81.2 & 146.3 & 41.5 & 138.2 & 44.5 & 90.3 & 50.0 & 84.1 & 59.6 & 84.8 & 39.5 & 67.0 & 21.8 \\
\hline 3-Ethylpentane & 11.37 & 8.8 & 14.7 & 4.5 & 13.2 & 6.9 & 9.6 & 4.3 & 8.7 & 6.1 & 8.6 & 4.1 & 6.9 & 2.2 \\
\hline Heptane & 12.03 & 91.9 & 164.6 & 53.6 & 147.4 & 43.2 & 100.1 & 54.4 & 76.6 & 58.3 & 80.8 & 43.4 & 64.8 & 17.3 \\
\hline 2,4-Dimethylhexane & 13.80 & 4.7 & 10.3 & 3.6 & 6.4 & 2.0 & 5.4 & 3.2 & 3.6 & 1.9 & 3.4 & 1.8 & 2.7 & 0.9 \\
\hline 2,3-Dimethylhexane & 15.44 & 2.9 & 7.4 & 2.9 & 40.2 & 5.6 & 11.8 & 16.0 & & & & & & \\
\hline 2-Methylheptane & 15.72 & 8.4 & 31.4 & 12.8 & 5.8 & 3.0 & 12.3 & 11.3 & 2.4 & 1.5 & 1.9 & 1.7 & 1.9 & 0.4 \\
\hline Octane & 17.82 & 11.8 & 39.2 & 19.2 & 13.7 & 5.3 & 17.8 & 12.9 & 2.9 & 1.9 & 2.7 & 2.1 & 2.4 & 0.5 \\
\hline 2,5-Dimethylheptane & 20.02 & 1.1 & 2.4 & 1.4 & 5.5 & & 2.6 & 2.0 & & & & & & \\
\hline 3-Methyloctane & 22.24 & 2.2 & 4.2 & 2.5 & 2.4 & & 2.8 & 0.9 & & & & & & \\
\hline 2,6-Dimethyloctane & 25.62 & & & & & & & & 1.6 & 1.8 & 1.7 & 1.7 & 1.7 & 0.1 \\
\hline 2-Methylnonane & 27.12 & 6.3 & 12.1 & 7.0 & 9.2 & 4.4 & 7.8 & 3.0 & 7.1 & 6.9 & 7.3 & 7.7 & 7.3 & 0.3 \\
\hline Decane & 28.81 & 32.3 & 61.2 & 42.1 & 81.3 & 31.8 & 49.8 & 21.3 & 35.8 & 48.9 & 45.1 & 58.4 & 47.0 & 9.3 \\
\hline Undecane & 33.10 & 110.0 & 126.9 & 152.8 & 189.2 & 155.2 & 146.8 & 30.2 & 64.6 & 114.3 & 89.7 & 162.1 & 107.7 & 41.6 \\
\hline Dodecane & 36.47 & 31.7 & 48.8 & 45.6 & 57.7 & 38.8 & 44.5 & 9.9 & 22.4 & 40.7 & 30.2 & 56.5 & 37.4 & 14.8 \\
\hline Tridecane & 39.13 & 4.5 & 5.4 & 5.6 & 7.3 & 6.3 & 5.8 & 1.1 & 2.4 & 5.4 & 2.4 & 7.0 & 4.3 & 2.3 \\
\hline Tetradecane & 41.34 & 2.0 & 2.5 & 3.1 & 4.2 & 2.8 & 2.9 & 0.8 & & 3.0 & 2.3 & 4.2 & 3.2 & 1.0 \\
\hline Pentadecane & 43.21 & 1.5 & 2.4 & 2.3 & & 4.0 & 2.5 & 1.0 & & & & & & \\
\hline Aliphatic compounds & & 486.5 & 824.6 & 446.5 & 878.4 & 425.2 & 612.2 & 220.3 & 316.6 & 353.4 & 365.5 & 393.7 & 357.3 & 27.9 \\
\hline 2-Butanone & 7.65 & & & & & & & & 3.0 & 2.3 & 1.4 & 5.3 & 3.0 & 1.7 \\
\hline Cyclohexanone & 23.91 & 2.3 & 3.3 & 2.4 & 5.0 & 2.7 & 3.1 & 1.1 & 2.5 & 5.5 & 2.5 & 3.8 & 3.6 & 1.4 \\
\hline Acetophenone & 32.22 & 4.1 & 7.1 & 5.6 & 9.3 & 3.0 & 5.8 & 2.5 & & & & & & \\
\hline Carbonyl compounds & & 6.4 & 10.3 & 8.0 & 14.4 & 5.8 & 9.0 & 3.5 & 5.5 & 7.7 & 3.9 & 9.1 & 6.5 & 2.3 \\
\hline Ethyl acetate & 8.21 & & & & & & & & 1.3 & 2.0 & 1.2 & 1.2 & 1.4 & 0.4 \\
\hline Butyl acetate & 18.60 & 7.0 & 4.3 & 17.1 & 2.3 & 2.3 & 6.6 & 6.2 & 4.8 & 7.5 & 4.9 & 7.4 & 6.1 & 1.5 \\
\hline
\end{tabular}




\begin{tabular}{|c|c|c|c|c|c|c|c|c|c|c|c|c|c|c|}
\hline Esters & & 7.0 & 4.3 & 17.1 & 2.3 & 2.3 & 6.6 & 6.2 & 6.1 & 9.5 & 6.1 & 8.6 & 7.6 & 1.8 \\
\hline 1-Butanol & 10.26 & 4.6 & 11.2 & 8.2 & 6.6 & 1.2 & 6.3 & 3.8 & 3.8 & 11.4 & 3.7 & 6.9 & 6.5 & 3.6 \\
\hline Phenol & 27.66 & 4.8 & 6.6 & 7.9 & 10.0 & 6.0 & 7.1 & 2.0 & 3.5 & 5.6 & 4.1 & 5.9 & 4.8 & 1.2 \\
\hline 2-Ethyl-1-hexanol & 30.09 & 28.2 & 46.0 & 45.7 & 69.2 & 16.7 & 41.1 & 20.0 & 17.2 & 34.9 & 22.9 & 38.5 & 28.4 & 10.0 \\
\hline Alcohols & & 37.5 & 63.8 & 61.8 & 85.7 & 23.9 & 54.5 & 24.2 & 24.5 & 51.9 & 30.7 & 51.3 & 39.6 & 14.1 \\
\hline$\alpha$-Pinene & 26.07 & 3.8 & 2.4 & 1.6 & 6.6 & 1.3 & 3.1 & 2.2 & 3.4 & 2.3 & 2.9 & 2.8 & 2.8 & 0.4 \\
\hline Limonene & 30.57 & 25.6 & 45.9 & 29.1 & 54.2 & 22.4 & 35.4 & 13.9 & 16.9 & 23.1 & 19.1 & 23.8 & 20.7 & 3.3 \\
\hline Terpenes & & 32.2 & 53.2 & 33.6 & 65.5 & 26.7 & 42.2 & 16.4 & 22.7 & 28.9 & 25.3 & 30.6 & 26.9 & 3.5 \\
\hline Total confirmed & & 840.6 & 1426.2 & 853.1 & 1515.9 & 706.7 & 1068.5 & 373.3 & 631.2 & 770.3 & 707.5 & 801.0 & 727.5 & 70.0 \\
\hline Other compounds & & 731.0 & 1330.3 & 969.6 & 1551.2 & 619.5 & 1040.3 & 394.6 & 575.5 & 847.0 & 650.4 & 972.6 & 761.4 & 181.5 \\
\hline Total VOC emission & & 1572 & 2756 & 1823 & 3067 & 1326 & 2109 & 762 & 1207 & 1617 & 1358 & 1774 & 1489 & 250 \\
\hline
\end{tabular}

(1) $\mathrm{t}_{\mathrm{R}}$ : retention time (min); ${ }^{(2)} \mathrm{SD}$ : standard deviation.
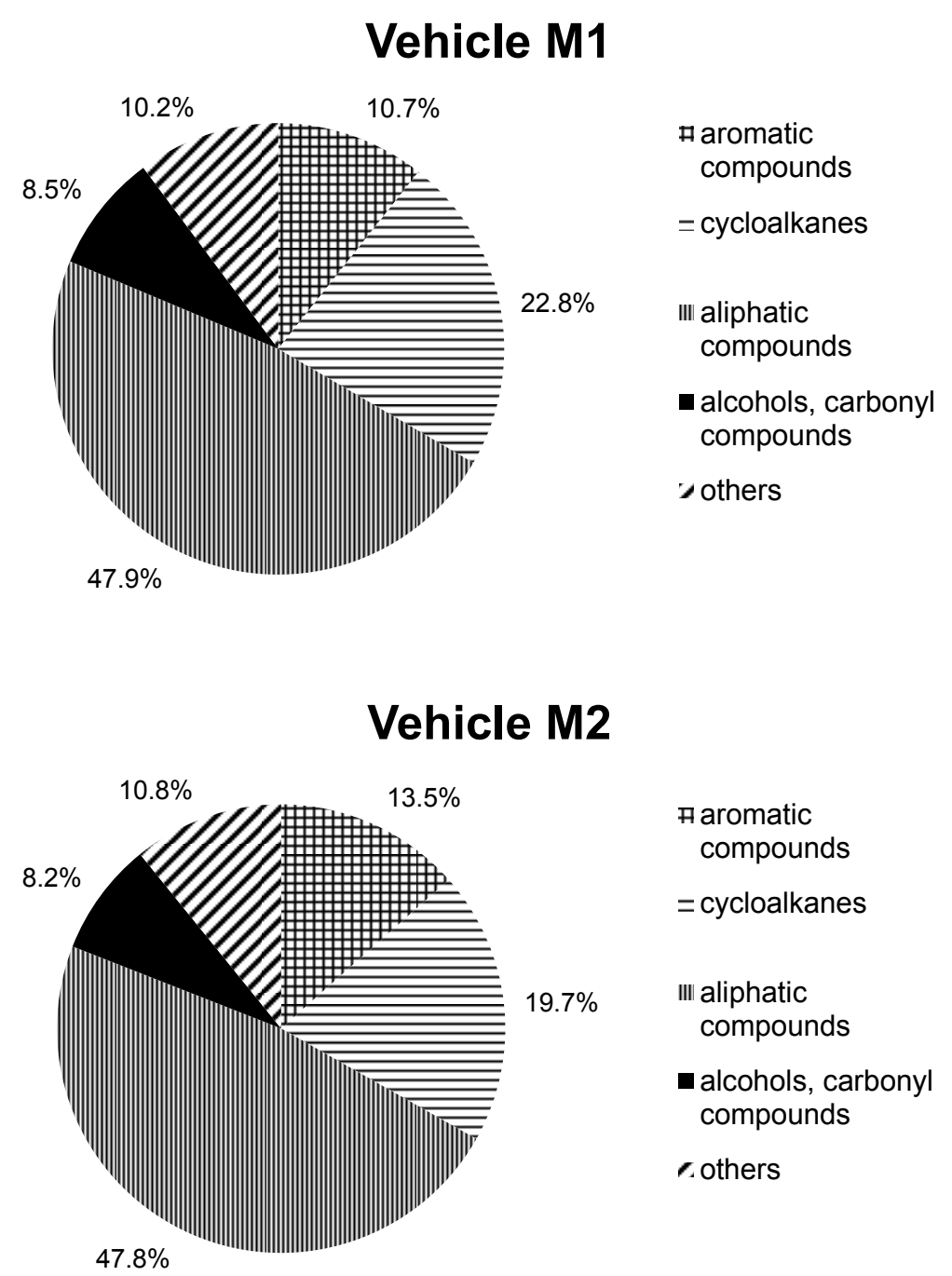
म aromatic compounds
= cycloalkanes
IIII aliphatic compounds
- alcohols, carbonyl compounds

cothers

Figure 1. Hydrocarbon groups share in total VOC emission

Concentrations and standard deviation of the mean between car examples for the main groups of compounds is presented in Figure 2. The highest dispersion of the results was observed for compounds containing an oxygen atom (alcohols, carbonyl compounds and esters, Table 1). The results obtained suggest, that in the case of those compounds, the time elapsed from the date of vehicle production to air sampling is of high importance. High values of RSD of the mean are also connected with the chemical and physical properties of sorbents employed. 


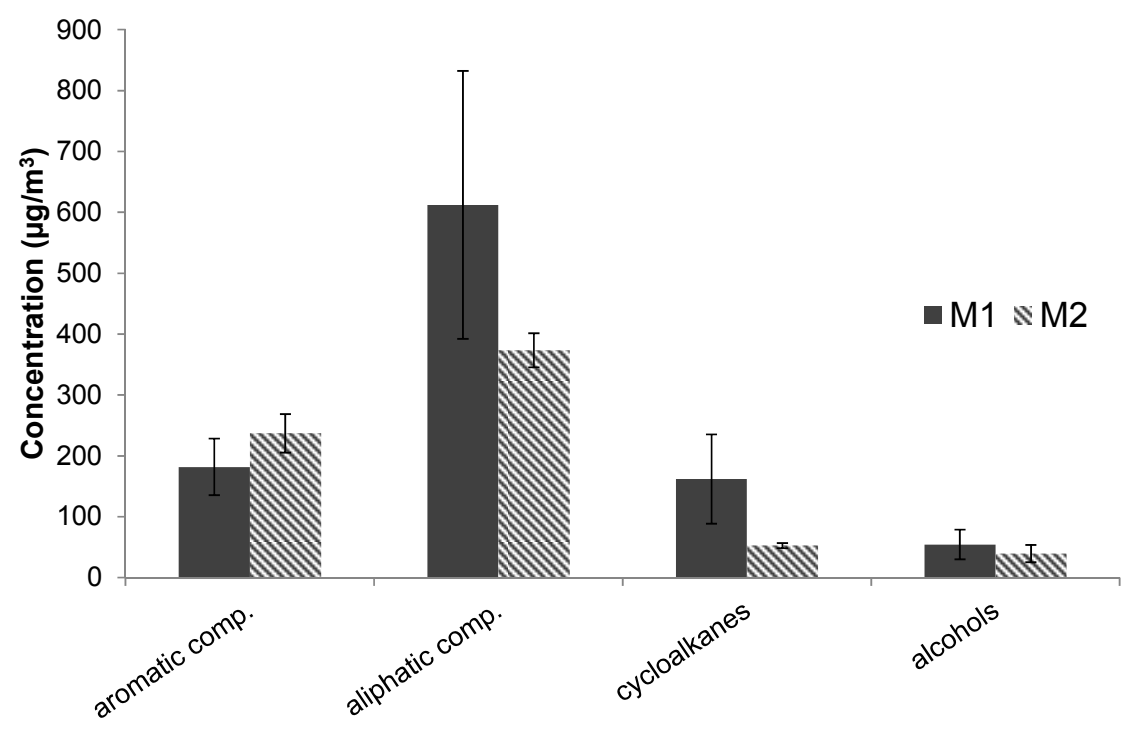

Figure 2. Concentration of different hydrocarbon groups with standard deviation of the mean

The average standard deviation of the mean for confirmed compounds was similar for cars M1 and M2 (17\% and $18 \%$, respectively). The results obtained mean that intra-model variability was lower than $20 \%$, which is better result to that presented by Chien (2007). The best reproducibility between the vehicles tested was observed for 1,2,4-trimethylbenzene, decane and naphthalene, while the worst reproducibility was observed for hexane and dimethylpentane. The values of relative standard deviation between vehicles tested revealed that the outfit M2 was much more repeatable in compounds concentrations than M1. The RSD values for the three main groups of organic compounds (aliphatic, aromatic and cyclic) in cars M2 was on the average level of $10 \%$, while in cars M1 it was $36 \%$, with the highest RSD value for aliphatic compounds (Figure 2).

The differences in interior equipment also affected the differences in particular compounds' presence and concentrations (Table 1). Styrene, trimethylbenzene, dimethyloctane and 2-butanone were observed only in cars M2, while methylcyclopentane, 2,6-dimethylcyclopentane, hexane and 2,5-dimethylheptane were characteristic for M1cars. On the other hand, compounds like heptane, octane and methylcyclohexane, were observed in both types of interior equipment, but their concentrations were significantly higher in M1 cars. Some of the compounds, benzene, toluene, ethylbenzene, isomers of xylene, ethyltoluene, naphthalene, 2-methylhexane, 1-butanol, $\alpha$-pinene or butyl acetate for example, were at similar concentration levels, irrespective of differences in interior equipment. This may suggest that those compounds were emitted by materials which are common to both types of equipment (for example headlining or carpet).

Among aliphatic hydrocarbons, undecane (110-189 $\left.\mu \mathrm{g} / \mathrm{m}^{3}\right)$, heptane $\left(54-165 \mu \mathrm{g} / \mathrm{m}^{3}\right)$ and 3-methylhexane $\left(42-146 \mu \mathrm{g} / \mathrm{m}^{3}\right)$ were the compounds with the highest concentrations in both types of interior equipment. A similar situation was observed in case of cyclic hydrocarbons, where methylcyclohexane, ethylcyclopentane and 1-methyl-3-propylcycohexane were the main compounds in both types of interior equipment. Toluene, 1-butyl-2-methylbenzene and $m$-xylene were the main aromatic hydrocarbons in M1 cars, while in M2 cars they were benzene, toluene and $m$-xylene.

The $t$-Student statistical test permitted the identification of compounds which were determined in vehicles with both types of interior equipment (among them: 1-butyl-2-methylbenzene, limonene, 1,2,4-trimethylbenzene, propylcyclohexane, undecane). Concentrations of 2-methylhexane, octane, 1-methyl-3-propylhexane were significantly higher in M1 vehicles' interiors than in M2. Some other compounds (i.e. methylcyclohexane or heptane) differed significantly in concentrations levels, depending on interior equipment. Since the dispersion observed for those compounds was high among the vehicles tested, it cannot be stated that the aforementioned compounds are characteristic of specific interior equipment.

Some of the unconfirmed compounds ('others') also had significant concentrations, among them were 4-methylundecane, decahydronaphthalene and 3,6-dimethyldecane.

For selected confirmed organic compounds a correlation between their concentration was designated (Table 2). In vehicles M2 a strong linear correlation between most of compared compounds was observed. Although some 
compounds can be emitted from different elements of vehicle interior equipment, the results suggest compounds with strong linear correlation originated from one source. In vehicles M1 a linear correlation was observed only in seven cases. The strongest correlation was observed for heptane and 3-methylhexane and for ethylbenzene and 2-ethylhexanol.

Table 2. Correlation between selected compounds concentrations, a) vehicles M1; b) vehicles M2

a)

\begin{tabular}{lllllllllll}
\hline No. & Compound & 1 & 2 & 3 & 4 & 5 & 6 & 7 & 8 & 9 \\
\hline 1 & heptane & 1.00 & & & & & & & & \\
2 & 3-methylhexane & 0.99 & 1.00 & & & & & & & \\
3 & undecane & 0.00 & 0.01 & 1.00 & & & & & & \\
4 & xylene isomers & 0.33 & 0.31 & 0.33 & 1.00 & & & & & \\
5 & ethylbenzene & 0.37 & 0.35 & 0.30 & 0.99 & 1.00 & & & & \\
6 & 3-ethyltoluene & 0.70 & 0.65 & 0.06 & 0.82 & 0.62 & 1.00 & & & \\
7 & 1,2,4-TMB ${ }^{(1)}$ & 0.23 & 0.27 & 0.72 & 0.74 & 0.70 & 0.48 & 1.00 & & \\
8 & phenol & 0.12 & 0.13 & 0.79 & 0.77 & 0.75 & 0.40 & 0.86 & 1.00 & \\
9 & 2-ethylhexanol & 0.45 & 0.43 & 0.33 & 0.98 & 0.99 & 0.86 & 0.79 & 0.77 & 1.00
\end{tabular}

(1) TMB - trimethylbenzene.

b)

\begin{tabular}{lllllllllll}
\hline No. & Compound & 1 & 2 & 3 & 4 & 5 & 6 & 7 & 8 & 9 \\
\hline 1 & heptane & 1.00 & & & & & & & & \\
2 & 3-methylhexane & 0.99 & 1.00 & & & & & & & \\
3 & 2,3-dimethylpentane & 0.98 & 1.00 & 1.00 & & & & & & \\
4 & xylene isomers & 0.65 & 0.65 & 0.67 & 1.00 & & & & & \\
5 & toluene & 0.93 & 0.91 & 0.90 & 0.85 & 1.00 & & & & \\
6 & 1,2,3- TMB ${ }^{(1)}$ & 0.93 & 0.94 & 0.95 & 0.85 & 0.96 & 1.00 & & & \\
7 & phenol & 0.87 & 0.89 & 0.91 & 0.88 & 0.92 & 0.99 & 1.00 & & \\
8 & limonene & 0.80 & 0.84 & 0.87 & 0.89 & 0.87 & 0.96 & 0.99 & 1.00 & \\
9 & 2-ethylhexanol & 0.85 & 0.89 & 0.91 & 0.87 & 0.90 & 0.98 & 1.00 & 1.00 & 1.00
\end{tabular}

(1) TMB - trimethylbenzene.

Test results obtained for cars M1 and cars M2 were compared. When comparing all the results, regarding confirmed and unconfirmed compounds, no linear correlation could be observed $\left(\mathrm{R}^{2}=0.32\right)$. The analytical range of compounds was divided into two sub-ranges on the basis of retention times of compounds. Compounds up to decane $\left(t_{R}=28.8 \mathrm{~min}\right)$ were characterized by stronger linear correlation $\left(\mathrm{R}^{2}=0.72\right)$ than compounds from decane onwards $\left(\mathrm{R}^{2}=0.13\right)$. The values determined indicate that compounds with boiling points lower than decane are present in tested vehicles at similar concentration levels, regardless of interior equipment. When comparing only confirmed compounds, a strong linear correlation can be observed $\left(\mathrm{R}^{2}=0.92\right.$, Figure 3$)$. 


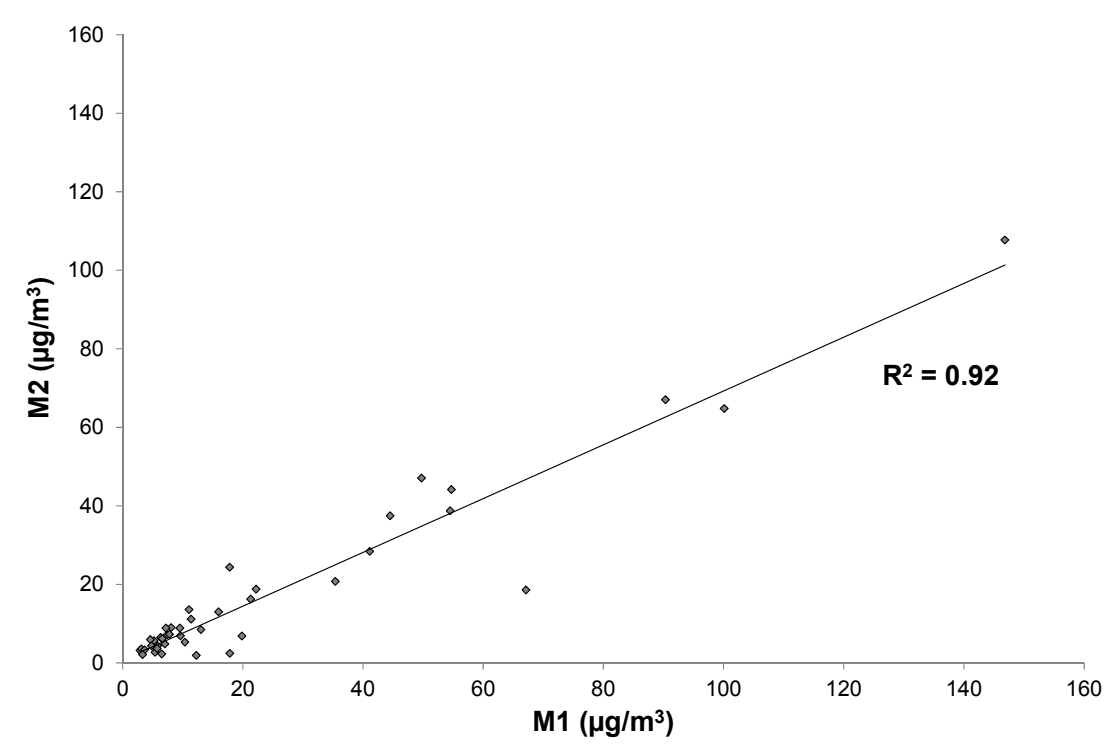

Figure 3. Correlation of confirmed compounds concentrations in different vehicles' interiors

\section{Conclusions}

The present study focused on examining air composition inside nine new vehicles. The vehicles under investigation were of the same model, but differed in terms of the materials used to equip the cabin. The M1 model's vehicles under study (M1_1...M1_5) had identical interior equipment. The same was true in the case of M2 interior equipment. The main differences involved materials in the upholstery and the steering wheel and dashboard colour. Described investigation is the first study where different examples of the same car model and interior equipment were examined. Accordingly, intra-model variability was possible to examine. It was also possible to examine the representativeness of air samples collection and air composition in different vehicles with identical interior equipment. On the basis of the results obtained it is possible to predict the air composition in another vehicle with the same interior equipment (with no changes in materials used). Therefore, an outlier vehicle can be pointed. It is very important information for the car producer.

The methodology applied for sampling and analysing volatile organic compounds permitted the identification of groups of compounds, which were responsible for $50 \%$ of organic compounds emission. Probably, more compounds could be identified and confirmed if more standard solutions were used. It was also possible to determine compounds with the highest concentrations, which were the main air pollutants inside vehicle's cabin. On the basis of the statistical tests performed it was possible to indicate compounds which were characteristic for each type of interior equipment. Taking into account that only new vehicles were examined, it can be stated that all compounds identified originated from off-gassing of interior materials.

\section{Acknowledgments}

This work was supported by National Centre for Research and Development (project No. NR10 004810).

\section{References}

AQS. (2006). Indoor air quality hazards of new cars. Air Quality Sciences Inc.

Brodzik, K., Faber, J., Łomankiewicz, D., \& Gołda-Kopek, A. (2014). In-vehicle VOCs composition of unconditioned, newly produced cars. Journal of Environmental Sciences, 26(5), 1052-1061. http://dx.doi.org/ 10.1016/S1001-0742(13)60459-3

Buters, J. T. M., Schober, W., Gutermuth, J., Jakob, T., Aguilar-Pimentel, A., Huss-Marp, J., ... Behrendt, H. (2007). Toxicity of parked motor vehicle indoor air. Environmental Science and Technology, 41, 2622-2629. http://dx.doi.org/10.1021/es0617901

Center for Environmental Research Information. (1999). U. S. EPA Method TO-17. U. S. EPA.

Chien, Y. Ch. (2007). Variations in amounts and potential sources of volatile organic chemicals in new cars. Science of the Total Environment, 382, 228-239. http://dx.doi.org/10.1016/j.scitotenv.2007.04.022 
Dettmer, K., \& Engewald, W. (2002). Adsorbent materials commonly used in air analysis for adsorptive enrichment and thermal desorption of volatile organic compounds. Analytical and Bioanalytical Chemistry, 373, 490-500. http://dx.doi.org/10.1007/s00216-002-1352-5

Faber, J., Brodzik, K., Gołda-Kopek, A., \& Łomankiewicz, D. (2013a). Benzene, toluene and xylenes levels in new and used vehicles of the same model. Journal of Environmental Sciences, 25(11), 2324-2330. http://dx.doi.org/0.1016/S1001-0742(12)60333-7.

Faber, J., Brodzik, K., Gołda-Kopek, A., \& Łomankiewicz, D. (2013b). Air pollution in new vehicles as a result of VOC emissions from interior materials. Polish Journal of Environmental Studies, 22(6), 1701-1709.

Faber, J., Brodzik, K., Łomankiewicz, D., Gołda-Kopek, A., Nowak, J., \& Świątek, A. (2012). Temperature influence on air quality inside cabin of conditioned car. Combustion Engines, 2(149), 49-56.

Fedoruk, M. J., \& Kerger, B. D. (2003). Measurement of volatile organic compounds inside automobiles. Journal of Exposure Analysis and Environmental Epidemiology, 13, 31-41. http://dx.doi.org/10.1038/sj.jea.7500250

Geiss, O., Tirendi, S., Barrero-Moreno, J., \& Kotzias, D. (2009). Investigation of volatile organic compounds and phtalates present in the cabin air of used private cars. Environment International, 35, 1188-1195. http://dx.doi.org/10.1016/j.envint.2009.07.016.

Grabbs, J. S., Corsi, R. L., \& Torres, V. M. (2000). Volatile Organic Compounds in new automobiles: screening assessment. Journal of Environmental Engineering, 974-977.

Idris, S. A., Robertson, C., Morris, M. A., \& Gibson, L. T. (2010). A comparative study of selected sorbents for sampling of aromatic VOCs from indoor air. Analytical Methods 2, 11, 1803-1809. http://dx.doi.org/10.1039/c0ay00418a

Ilgen, E., Levsen, K., Angerer, J., Schneider, P., Heinrich, J., \& Wichmann, H. E. (2001). Aromatic hydrocarbons in the atmospheric environment. Part III: personal monitoring. Atmospheric Environment, 35, 1265-1279.

Jo, W. K., \& Park, K. H. (1999). Concentration of volatile organic compounds in the passengers side and the back seat of automobiles. Journal of Exposure Analysis and Environmental Epidemiology, 9, 217-227.

Kalman, E. L., Löfvendahl, A., Winquist, F., \& Lundström, I. (2000). Classification of complex gas mixtures from automotive leather using an electronic nose. Analytica Chimica Acta, 403, 31-38. http://dx.doi.org/10.1016/ j.snb.2012.07.021.

Klepeis, N. E., Nelson, W. C., Ott, W. R., Robinson, J. P., Tsang, A. M., Switzer, P., ... Engelmann, W. H. (2001). The National Human Activity Pattern Survey (NHAPS): a resource for assessing exposure to environmental pollutants. Journal of Exposure Analysis and Environmental Epidemiology, 11, 231-252.

Mandalakis, M., Stephanou, E. G., Horii, Y., \& Kannan, K. (2008). Emerging contaminants in car interiors: Evaluating the impact of airborne PBDEs and PBDD/Fs. Environmental Science and Technology, 42, 6431-6436. http://dx.doi.org/10.1021/es7030533

Pankow, J. F., Luo, W., Isabelle, L. M., Bender, D. A., \& Baker, R. J. (1998). Determination of a wide range of volatile organic compounds in ambient air using multisorbent adsorption/thermal desorption and gas chromatography/mass spectrometry. Analytical Chemistry, 70, 5213-5221. http://dx.doi.org/10.1021/ac980 $481 \mathrm{t}$

Rahman, Md. M., Kim, K.-H. (2012). Exposure to hazardous volatile pollutants back diffusing from automobile exhaust systems. Journal of Hazardous Materials, 241-242, 267-278. http://dx.doi.org/10.1016/j.jhazmat. 2012.09.042.

Riediker, M., Williams, R., Devlin, R., Griggs, T., Bromberg, P. (2003). Exposure to Particulate Matter, Volatile Organic Compounds, and other air pollutants inside patrol cars. Environmental Science and Technology, 37, 2084-2093. http://dx.doi.org/10.1021/es026264y.

Schupp, T., Bolt, H. M., Jaeckh, R., Hengstler, J. G. (2006). Benzene and its methyl-derivatives: Derivation of maximum exposure levels in automobiles. Toxicology Letters, 160, 93-104. http://dx.doi.org/10.1016/j.toxlet. 2005.06.012.

Weisel, C. P. (2005). Automobile, Bus, and Rail Passenger Air Quality. HDB Env. Chemistry, 4(H), 317-334. http://dx.doi.org/10.1007/b107250. 
Yoshida, T., \& Matsunaga, I. (2006). A case study on identification of airborne organic compounds and time courses of their concentrations in the cabin of a new car for private use. Environment International, 32, 58-79. http://dx.doi.org/10.1016/j.envint.2005.04.009.

Yoshida, T., Matsunaga, I., Tomioka, K., \& Kumagai, S. (2006a). Interior air pollution in automotive cabins by volatile organic compounds diffusing from interior materials: I. Survey of 101 types of Japanese domestically produced cars for private use. Indoor and Built Environment, 15 (5), 425-444. http://dx.doi.org/10.1177/1420 $326 \times 06069395$

Yoshida, T., Matsunaga, I., Tomioka, K., \& Kumagai, S. (2006b). Interior air pollution in automotive cabins by volatile organic compounds diffusing from interior materials: II. Influence of manufacturer, specifications and usage status on air pollution, and estimation of air pollution levels in initial phases of delivery as a new car. Indoor and Built Environment, 15 (5), 445-462. http://dx.doi.org/10.1177/1420326X06069462.

You, K., Ge, Y., Hu, B., Ning, Z., Zhao, S., Zhang, Y., \& Xie, P. (2007). Measurement of in-vehicle volatile organic compounds under static conditions. Journal of Environmental Sciences, 19(10), 1208-1213.

Zhang, G. S., Li, T. T., Luo, M., Lin, J. F., Lin, Z. R., \& Bai, Y. H. (2008). Air pollution in the microenvironment of parked new cars. Building and Environment, 43, 315-319. http://dx.doi.org/10.1016/j.buildenv.2006. 03.019

\section{Copyrights}

Copyright for this article is retained by the author(s), with first publication rights granted to the journal.

This is an open-access article distributed under the terms and conditions of the Creative Commons Attribution license (http://creativecommons.org/licenses/by/3.0/). 